\title{
Effects of anaerobic exercise on some coagulation factors in non- athletes female students of Islamic Azad University of Sanandaj
}

\author{
Mohsen Foroughi ${ }^{1}$, Ellahe Fakhr Tabatabai $^{2}$ \\ ${ }^{1}$ M.A. of Physical Education, Teacher of Borojerd Educational Organization, Borojerd, Iran \\ ${ }^{2}$ School of Sport Science and Physical Education, Azad University of Borojerd, Borojerd, Iran \\ E-mail address: moh.foroughi@gmil.com
}

Keywords: blood coagulation; fibrinolysis; anaerobic activity; fibrinogen; platelets; Prothrombin, Partial thromboplastin

\begin{abstract}
The purpose of the present research is compare the effects of coagulation factors in nonathletes gilrs after exhaustive anaerobic activity .Present study was semi-emprical that was done on 12 non-athlete female students in range of 18-24 years. Exercise protocol was RAST test, that in which each person passed amain 35 meters of distance for 6 times and rest 10 seconds between each stage.Blood sampling was performed in two stages (before and after).Datas were analyzed with Kolmogorov Smirnov test, Levine's test and two-way ANOVA level $(p<0 / 05)$. The results showed that anaerobic exercise had a significant influence on partial time Thromboplastin (PTT), and fibrinogen in non-athletic subjects.But there was not significative difference on Prothrombin time (PT), platelet and hematocrit.Findings suggested that a meeting of anaerobic exercise on blood coagulation factor, effectiveness and changes in some of the invoices for training program Drafradghyrfal is important.
\end{abstract}

\section{INTRODUCTION}

Today, sportive and physical activities and its effects on various organells of the body is under consideration so, much information has been obtained. Researchs and studies in this field have shown that sport and exercise has a positive effect on efficiency and keeping the body healthy (5).However, if physical activity does not done regularly and correctly in accordance of scientific standards, it would not be useful, so would be dangerous for health. According to professionalizing of the sport and earning a better record, athletes need a serious and regular exercise. Since individuals in these activities should to bear high pressure, different views has occurred about of intensity of activities. Some of scientists are opposed of excessive exercises, and some of others have confirmed it. Thus a new chapter and subject in research of sports began and researchers are investigating the relationship between vigorous activity with the mechanisms of the human body(8). One of the major systems of body that are affected by physical exercise is blood coagulation so lifelessness of systems depends on blood coagulation. Blood clotting is an amazing machine that produces clots in the arteries and cause hemostasis. However improper and uncontrolled its activity accommodating with active coagulation of blood clot cause death. In normal conditions, this system regulate by regulators. To keeping these condition and equilibrium, coagulation factors, regulatory proteins and cells are very impressive(6). Sudden physical exertion is associated with an increased risk of acute myocardial infarction and sudden cardiac death. In addition, activation of the coagulation cascade and/or reduced fibrinolytic capacity after physical exercise has been reported in patients with cardiovascular disease (13).

Researches done on the effects of exercise and sport on blood coagulation factors has provided mixed results._Submaximal exercise does not affect on the PT, PTT, but count is increased hematocrit and platelet (3). 
Ghanbari Niaki and Shahrbano Mohammadi ( 1388) Survey of anaerobic exercise on hematological changes were observed in male boxers cake, there was no significant change in hematocrit and platelets ( 4 ). Hansen and associates (2001) in their study concluded that increased activity level of coagulation eight factor and fibrinolysis ( 17 ). In another study, colon and colleagues (1997) reported increased catabolism of fibrinogen and plasminogen looking physically strenuous activity but did not observe significant changes in PT ( 14 ). Naylyn ( 2007) With Survey Platelet activity, coagulation and fibrinolysis during exercise in healthy men exercise increases the concentration of platelets and leukocytes were observed independent of coagulation and fibrinolysis by thrombin is increased but the balance between the sport seems to be maintained ( 26 ). Quinn (2009) stated fibrinolytic activity in postmenopausal women could be improved by 3 weeks of regular training programs under the maximum (21).. Madarameh et al (2010) concluded after exercise any of the variables prothrombin complex thrombin - antithrombin 3 and D.Dimer type did not change significantly ( 24 ). According to Different results of this study and other similar studies, in conjunction with the effect of anaerobic exercise on blood coagulation factors in the present study efforts examined the affect of this exercises on blood coagulation system of non-athletes persons.

\section{MATERIALS AND METHODS}

The semi-experimental study were performed on non-athletes female students 24-18 years of Islamic Azad University of Sanandaj. At first was announced public recall in Azad University of Sanandaj. According to a questionary information, said they were cooperating in this investigation, 47 cases were ready for trial. From between this number, the 12 person of non-athletes female students 18-24 years, who were all eligible to participate in the plan, as a non-athletes female group were investigated.

All subjects completed a questionnaire based on questions on a minimum of two years experience in any regular physical activity. The history of hematological disease, and heart disease Were non-smokers and were not taking drugs, particularly when doing research. A few days before the test, done the initial coordination with the authorities of clinical laboratories the city of Sanandaj and with help of the partners has been held a meeting for the detection of fitness and familiarity with the test subjects.

Two days before the exam, final coordination was done with research colleagues and taken to the laboratory and the subjects were asked to measure and criteria mentioned above at 8 am in fasting Sanandadj, Islamic Azad University gym ISG and were ordering to them that they did not have any physical activity 48 hours before sampling. Subjects rested for 30 minutes before starting the test. In rest period, the first stage of sampling (pre-test) was done this order at before exercise and were taken blood samples.

Then researcher divided the participants into two groups and were taken the physical test (RAST test). Immediately after completion of the test, by expert clinical laboratory blood samples were taken from both, in Hall. In desired test (RAST test) subject running at full speed 6 times the 35 meters of distance and does the rest between each 35 meters for 10 seconds. Received Information were recorded on data collection forms from each subject. Second blood samples were taken after exercise (post-test) immediately.

From The device coaglumeter Coatron Made in Germany for measured fibrinogen Factors PT And PTT. Plant Cell Counter - Coulter T-890-CoulTer Made in America and device for measuring hematocrit and platelet was used. In this study, the analysis was used by Kolmogorov Smirnov test and Levine's test for homogeneity of variance and two-way analysis of variance Level $(p<0 / 05$ Collection). 


\section{RESULTS}

There was not significant PT-time changes in non-athletic subjects in the pre-test and post-test (Table I).

Table 1. Statistical IndicatorsTime PT

\begin{tabular}{|c|c|c|c|c|c|}
\hline \multirow{2}{*}{ Statistics } & \multicolumn{2}{|c|}{ The mean and standard deviation } & \multirow{2}{*}{$\begin{array}{l}\text { Percent of } \\
\text { change }\end{array}$} & \multirow{2}{*}{ T-dependent } & \multirow{2}{*}{$\begin{array}{c}\text { Significant } \\
\text { level }\end{array}$} \\
\hline & Pretest & Posttest & & & \\
\hline$(\mathrm{p}<0 / 05)$ & $12 / 42 \pm 0 / 76$ & $12.53 \pm 0.74$ & +0.88 & -1.4 & 0.19 \\
\hline
\end{tabular}

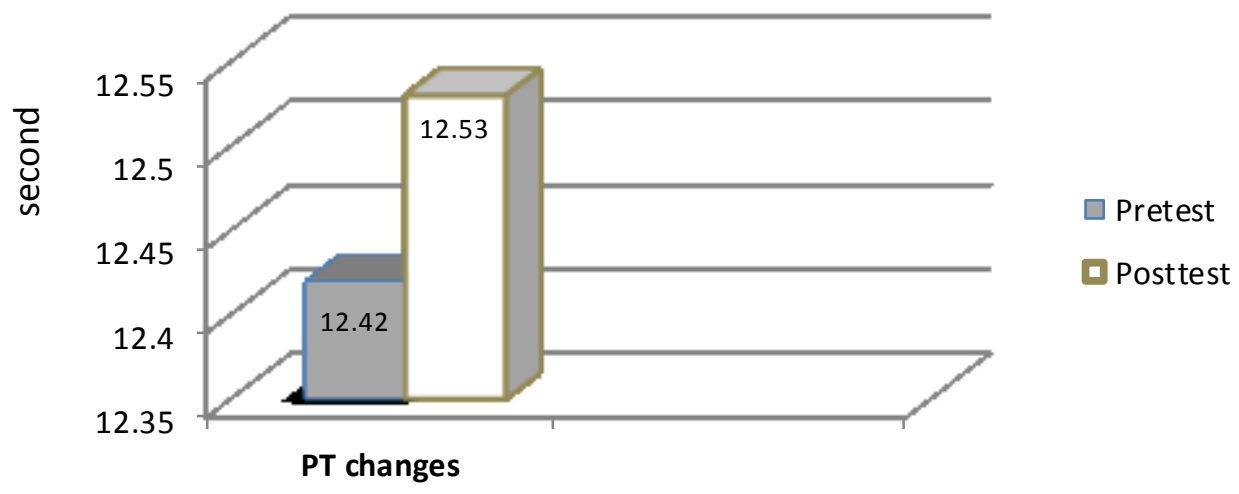

Time changes PTT pre-test, post-test was statistically significant. And it was found that anaerobic exercise reduces time PTT (Table 2).

Table 2. Statistical indicators of Partial thromboplastin time PTT

\begin{tabular}{|c|c|c|c|c|c|}
\hline \multirow{2}{*}{ Statistics } & \multicolumn{2}{|l|}{ The mean and standard deviation } & $\begin{array}{c}\text { Percent of } \\
\text { change }\end{array}$ & T-dependent & $\begin{array}{c}\text { Significant } \\
\text { level }\end{array}$ \\
\cline { 2 - 5 } & Pretest & Posttest & & 2.43 & 0.03 \\
\hline
\end{tabular}

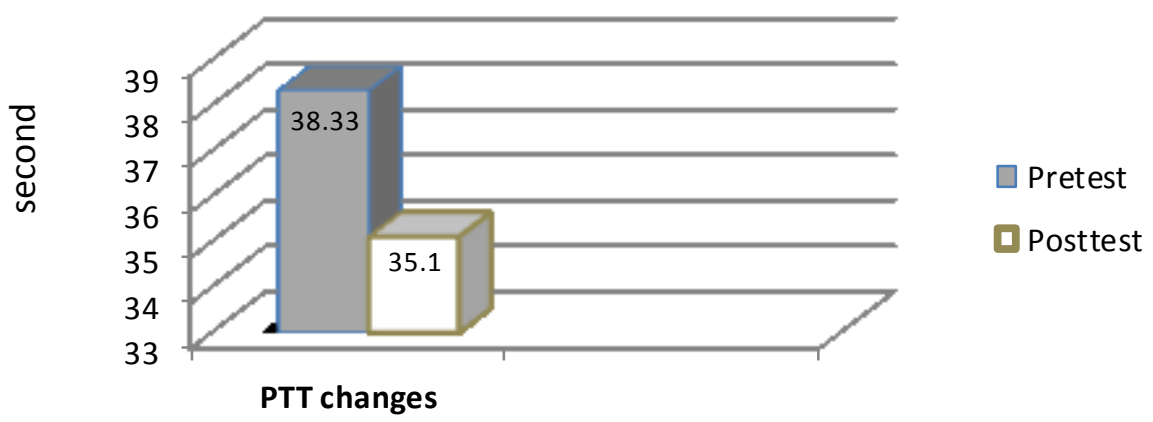


T-test was used to determine the hematocrit value of non-athletic subjects in two stages (pre-test and post-test) were not significantly different (Table 3 ).

Table 3. Statistical indicators of hematocrit HCT

\begin{tabular}{|c|c|c|c|c|c|}
\hline \multirow{2}{*}{ Statistics } & \multicolumn{2}{|l|}{ The mean and standard deviation } & $\begin{array}{c}\text { Percent of } \\
\text { change }\end{array}$ & T-dependent & $\begin{array}{c}\text { Significant } \\
\text { level }\end{array}$ \\
\cline { 2 - 3 } & Pretest & Posttest & & -1.92 & 0.08 \\
\hline
\end{tabular}

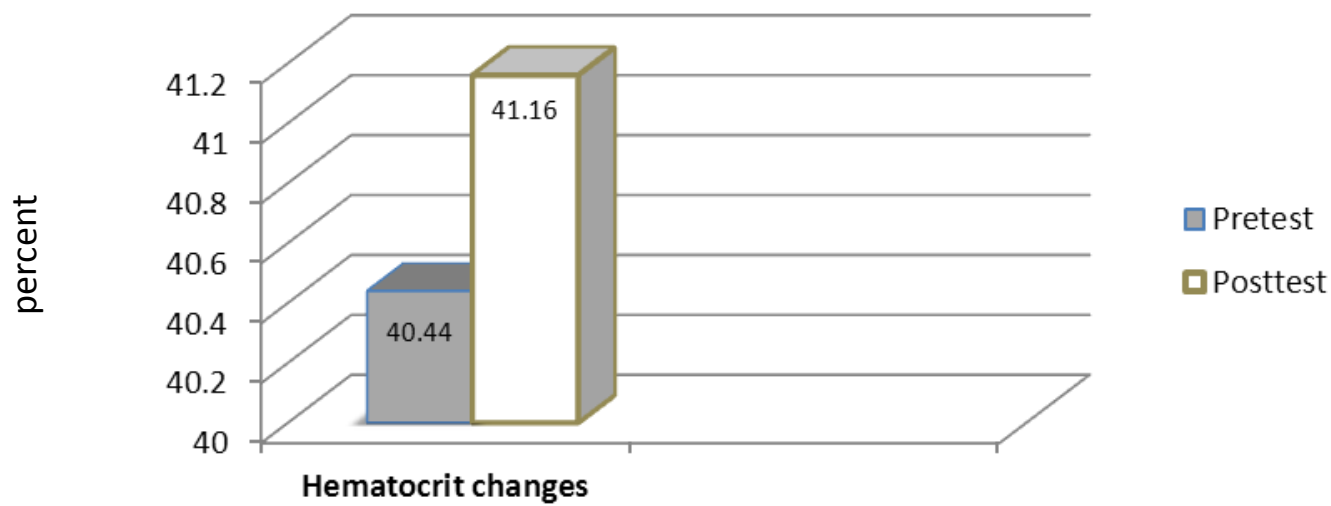

T-test in non-athletic subjects, was not observed significant differences in the number of blood platelets in two stages (pre-test and post-test) (Table 4).

Table 4. Statistical parameters of platelet PLT

\begin{tabular}{|c|c|c|c|c|c|}
\hline \multirow{2}{*}{ Statistics } & \multicolumn{2}{|c|}{ The mean and standard deviation } & \multirow{2}{*}{$\begin{array}{c}\text { Percent } \\
\text { of } \\
\text { change }\end{array}$} & \multirow{2}{*}{ T-dependent } & \multirow{2}{*}{$\begin{array}{c}\text { Significant } \\
\text { level }\end{array}$} \\
\hline & Pretest & Posttest & & & \\
\hline$(\mathrm{p}<0 / 05)$ & $243083.3 \pm 52044.5$ & $249250.01 \pm 51638.8$ & +2.6 & -1.46 & 0.17 \\
\hline
\end{tabular}

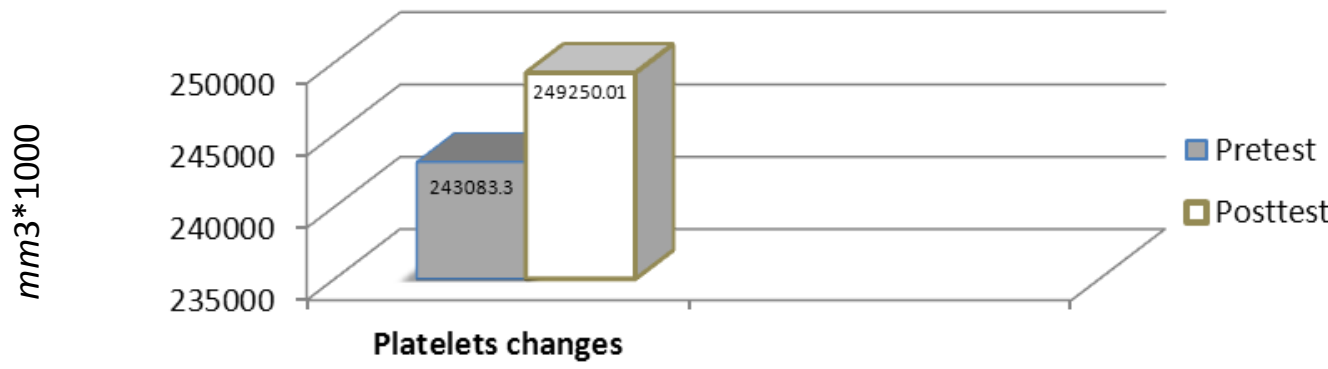

T-test was used to determine that there are significant differences in amount of fibrinogen in the blood of non-athletic subjects in two stages (pre-test and post-test), that was observed increase in fibrinogen (Table 5). 
Table 5. Statistical Indicators of fibrinogen

\begin{tabular}{|c|c|c|c|c|c|}
\hline \multirow{2}{*}{ Statistics } & \multicolumn{2}{|l|}{ The mean and standard deviation } & \multirow{2}{*}{$\begin{array}{c}\text { Percent of } \\
\text { change }\end{array}$} & T-dependent & $\begin{array}{c}\text { Significant } \\
\text { level }\end{array}$ \\
\cline { 2 - 5 } & Pretest & Posttest & & -2.29 & 0.04 \\
\hline
\end{tabular}

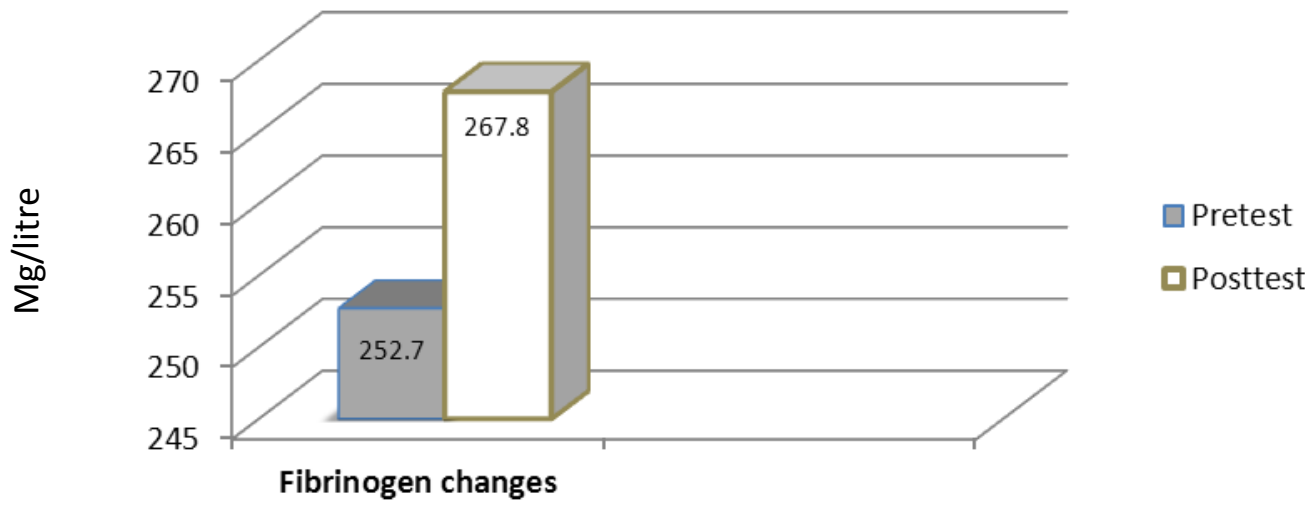

\section{DISCUSSION}

In this study the influence of an intense activity session on coagulation factors of non-athles female students was examined. During this Study was tried as much as possible to be determined the effect of sports activity on variables research parameteres and the effect of other Factors Like anthropometric changes, age and the feeding minimize. Results of this study showed that the activity of coagulation factors, some factors increase and some decrease. From view of Gonzalez (2006) and Smith (2002), these changes in healthy athletes as physiological reactions, without any clinical symptoms in is used $(28,15)$. Factors such as Fibrinogen has an important role in myocardial infarction and stroke and on the other hand $16.7 \%$ of all cases of cardiac death associated with exercise during or shortly after it (27).

Physical can Cause aberrant stimulation of Coagulation Blood system and also can prevent it. Because of doing physical activity by non athlete persons so studing of the Homeostasis and process of Coagulation Blood after exercise are very important, specifically comparison of response of these systems to exercise is considerable. Group response to activity showed that there was not a significant difference between their PT in two periods (before and immediately after the test) that this results are same results of Cullen et al (1997) saw no PT change with activity in healthy nonathletes men respectively (14).

PT is extrinsic pathway of coagulation initiation and shorting of it is dependent on the concentration of prothrombin. Reduced of it have direct relationship with increase of Thrombin generation. Athletic activity cause Increase of Production of Thrombin and Likely To Cause Expression tissue factor at now Circulation The Is that with athletic activity ancrease the finds. It is likely that changes PT physical activity may depend on the type and severity (23).

Radmehr (1383) and Ghanbari Niaki (1388) have shown that activity using various training programs has no significant effect on PT (3.4) but Habibian (1388) and Aray (2008) have reported a significant increase or decrease its $(1,11)$, It is likely that PT changes may depend on the type and severity of in physical activity. Mousavi and colleagues (1388) showed that PT is significantly decreased after aerobic and resistance exercise (7).

PTT test subjects immediately after $9 / 8 \%$ decline significantly . PTT is one of the coagulation indicators that is slower than PT and with a damaged blood vessel wall is damaged and contact with 
the collagen mechanism begins and the indicators inside track .Exercise can cause endothelial cell activation and stimulates the secretion of Fon Willebrand Factor ( 22 ). Halter and colleagues (2002 ) showed a significant decrease in PTT after intense activity was demonstrated in healthy subjects ( 16 ).

Hematocrit is expressed as a percentage as compared to the total volume of red blood cells in blood ( 2 ) low hematocrit is a sign of anemia. and In situations such as reduced plasma volume (in dehydration ) and or when the red blood cells is increased (like be in height), its value will increase. In the present study, hematocrit showd 78/1\% from pre-test to post-test, but was not statistically significant. Its results are consistent with previous results of Mac Naughton and colleagues research (2006)that have observed that the effect of exercise on hematocrit ( 25 ).

Some researchers have reported an increase in hematocrit after physical activity. Radmehr (1383) showed Increase of hematocrit after submaximal and maximal exercise in sedentary women (3) that is likely this changes depends to type of test and duration on the activity.

The number of platelets increased in the post-test stage, 6/2 percent.that but was not significant . Asghari (2009) have shown that exercise causes platelets to increase. Increased levels of platelet release of new platelets could be related to the vascular bed of the spleen and bone marrow as well as the release of epinephrine, which causes contraction of the spleen, where about a third of platelets are stored in it , and since during physical activity release of epinephrine is increased mechanism can explain the increase in cycle sport in platelet count ( 10$)$. Buri and Santro (2003) observed an increase in platelets after vigorous activity ( 12 ) The results of this study also has similar Ikaroogi et al research (2008) ( 18 ).

Fibrinogen in response to anaerobic activity from pre-test to post-test, $9 / 5 \%$ increase that the increase was significant. Fibrinogen is an important matter of the coagulation cascade and is a major determinant of blood flow viscosity, high fibrinogen levels are associated with increased risk of cardiovascular disease (20) Fibrinogen Changes is related to differences in size of plasma (9) Some researchers increased or decreased fibrinogen using different training programs Dah that may change due to exercise intensity, fitness level and type of activity. . Colon and colleagues (1997) were demonstrated Increased fibrinogen after intense physical activity of healthy untrained men (14).

\section{CONCLUSION}

According to the present study a anaerobic activity session cause activation some of clotting factors in the blood. Practical results of the present research show that although physiological responses of body did not difference significant to the challenges of physical activity in people in some pretty factor,but changes in certain factors in non- active people is important for design the exercise program. Based on the results we can say that order the exercise program for the common people, the elderly and patients, especially patients with clotting problems and cardiovascular disease and exercise program should be cautious. This results at planning Intensity of exercise for the non-active people Particular at top Period These Sour Help The Will It was suggested that more research. Researcher refers to doing more research on this factors for the effects of long term exercise on people with different ages.

\section{ACKNOWLEDGMENT}

With many thanks to the participants and officials from the Islamic Azad University of Sanandaj, that present study was not possible without the cooperation of these ones undoubtedly. 


\section{References}

[1]. Habibiyan M., Tejari F. , Mousavi Gilani , SR , Mousavi , Seyedjafar ; (1388 ) compared the effects of a aerobic session and resistance exercise on the activity of coagulation factors in healthy women, Journal of Materials Science and Engineering, Volume 12, Number 4, 33 37

[2]. Dorland V. (2004) Dorland Medical Dictionary,Golban Publications with Arian teb and and Ghazi jahani .

[3]. Radmehr A., (1383) Comparison of maximal and submaximal exercise on blood clotting time female student -athlete Islamic Azad University of Tabriz, , MS Thesis in Physical Education . Islamic Azad University of Tehran .

[4]. Ghanbari niaki ; Mohammadi , SH , (1388) The effect of four weeks of aerobic exercise on plasma Lypoprotein boxers man cake hematologic changes, letter of Applied Exercise Physiology / 5th Year/ tenth No./ Autumn and Winter, 88 , pp. 75-87

[5]. Ghanbari Niaki, A., Tayebi S. M., Dolroz H., (1390), Effects of eccentric resistance exercise on blood coagulation factors in students idle boy ; journal Blood, Volume VIII , Number 3 , 195-206

[6]. Golafshan, H. (1378), Foundations of anticoagulant and laboratory procedures .Koushamehr Publications.

[7]. Mousavi, Seyedjafar, Habibiyan, M. (1388), Comparison of two methods of acute aerobic and resistance of plasma fibrinogen concentration in young women Journal of Gorgan University of Medical Sciences, Thirteen Year, Number 4 ( 40 )

[8]. Mirzaei Ghaziani, B. , ( 1376). Significant changes in blood cortisol peak morning and evening cleansing makers elected by the people of Gilan in practice. Master Thesis in Physical Education . University of Guilan.

[9]. Ahmadizad S, EL-Sayed MS. (2005); The acute effects of resistance exercise on the main determinants of blood rheology. J Sports Sci 23:243-249.

[10]. Arazi H, Asghari E. Lotfi P. (2009). "Effects of an exercise session and preparing special kung fu skills on hematologic variables, exercise physiology and physical education. p.235240.

[11]. Arai, Mario .Hisashi, Yorifuji. Shojiro, Ikematsu. Hiroshi, Nagasawa Michio, Fujimaki, (2008). Influences of strenuous Exercise on blood coagulation and fibrinolytic system.

[12]. Bourey RE, Santoro SA, ( 2003) . Interaction of exercise $\mathrm{m}$ coagulation, platelets, and fibrinolysis. Med sci sports Exerc, 20 ( 5 ) : 439 - 446 .

[13]. D. Collen, N. Semeraro, J. P. Tricot, and J. Vermylen;(1997); Turnover of fibrinogen, plasminogen, and prothrombin during exercise in man

[14]. Eriksoon -Berg, Margita .Egberg, Nils . Eksborg ,staffan . schenck - Gustafsson , Karin , (2002) .Retained fibrinolytic response and on coagulation activation after acute physical exercise in middle - aged women with previous myocardial in farction . Thrombosis Research, 105: $481-486$.

[15]. Gonzales, F .Manas M, Seiquer I, Quiles I , Mataix FJ , Huertas JR, et al , (2006) .Blood platelet function in healthy individuals of different ages. Effect of exercise and exercise conditioning. J sports Medphys fitness, 36: $112-116$.

[16]. Hulter M, Beneker , Kirsch K., et al , (2002) .Markers of coagulation, fibrinolysis and angiogenesis after strenuous short - term exercise ( wingate - test ) in male subjects of varuing fitness hevels . intg sports med , 23: $489-494$. 
[17]. Hansen J. B., Svensson, Zhang C. L., Lgngmov, Nordoy A., (2001). Basal plasma concentration of tissue Plasminogen activator $(\mathrm{t}-\mathrm{PA})$ and The adaption to strenuous exercise in familial hyper cholesteralaemia ( F H ). Blood coagul Fibrinolysis , 5 : $781-787$

[18]. I karugi Hideo. Masashi Shibata Shiorishibata. Hiromitsulshii. Tomomi Taka. Junichiro Yamamoto, (2008). High Intensinty Exercise Enhances Platelet Reactivity to shear stress and coagulation during and after Exercise PathophysiolHaemostThromb, $33: 127$ - 133 .

[19].Kahraman S, Demirkan F, Bediz C, Alacacioglu I, AksuI(2007); The effect of exercise on fibrinolytic and coagulation systems in healthy volunteers. J ThrombHaemost Supplement 2: PS-362.

[20].Kamath S, Lip GY (2003). Fibrinogen: biochemistry, epidemiology and determinants. QJM. Oct;96(10):711-29

[21].Kevin HD, Osterud B., (2009) .The effect of physical conditioning suggests adaptation in procoagulant and fibrinolytic potential. Thromb Res, 87: $559-569$.

[22].Lekakis J, Triantafyllidi H, Galea V, et al. The immediate effect of aerobic exercise on haemostatic parameters in patients with recently diagnosed mild to moderate essential hypertension. J Thromb Thrombolysis 2008; 25(2): 179-84.

[23].Lund, T., Kvernmo, H.D., Osterud, B. (1998). Cellular activation in response to physical exercise: the effect of platelets and granulocytes on monocyte reactivity. Blood Coagul Fibrinolysis. 9: 63-69

[24].MadarameHaruhiko (2010).Effects of low-intensity resistance exercise with blood flow restriction on coagulation system in healthy subjects.DOI: 10.1111/j.1475-097X.2010.00927.x

[25].MC naughton LR; (2006).Plasma Volume response associated with a sprint triathlon in novice triathlets. INT J sport med; 10: 161-164

[26].Nailin Li.(2007). Platelet Activity, Coagulation, and Fibrinolysis During Exercise in Healthy Males.Arteriosclerosis, Thrombosis, and Vascular Biology.2007; 27: 407-413

[27].Rezaiean Z, Torkaman G, Nadali F.2006, Effect of physical fitness on the coagulate activity of healthy young men. Pak J BiolSci 2006; 9:2032-2039.

[28].Smith, JE,( 2002). Effects of strenuous exercise on homeostasis. J Sport Med, 37: 433 - 435. 